\title{
Predicting surgical resource consumption and in-hospital mortality in resource-scarce conflict settings: a retrospective study
}

\author{
Måns Muhrbeck ${ }^{1,2^{*}}$ (D), Zaher Osman ${ }^{3}$, Johan von Schreeb ${ }^{4}$, Andreas Wladis ${ }^{1,2}$ and Peter Andersson ${ }^{1,5}$
}

\begin{abstract}
Background: In armed conflicts, civilian health care struggles to cope. Being able to predict what resources are needed is therefore vital. The International Committee of the Red Cross (ICRC) implemented in the 1990s the Red Cross Wound Score (RCWS) for assessment of penetrating injuries. It is unknown to what extent RCWS or the established trauma scores Kampala trauma Score (KTS) and revised trauma score (RTS) can be used to predict surgical resource consumption and in-hospital mortality in resource-scarce conflict settings.

Methods: A retrospective study of routinely collected data on weapon-injured adults admitted to ICRC's hospitals in Peshawar, 2009-2012 and Goma, 2012-2014. High resource consumption was defined as $\geq 3$ surgical procedures or $\geq 3$ blood-transfusions or amputation. The relationship between RCWS, KTS, RTS and resource consumption, inhospital mortality was evaluated with logistic regression and adjusted area under receiver operating characteristic curves (AUC). The impact of missing data was assessed with imputation. Model fit was compared with Akaike Information Criterion (AIC).
\end{abstract}

Results: A total of 1564 patients were included, of these 834 patients had complete data. For high surgical resource consumption AUC was significantly higher for RCWS $(0.76,95 \% \mathrm{Cl} 0.74-0.78)$ than for KTS $(0.53,95 \% \mathrm{Cl} 0.50-0.56)$ and RTS $(0.51,95 \% \mathrm{Cl} 0.48-0.54)$ for all patients. Additionally, RCWS had lower AIC, indicating a better model fit. For in-hospital mortality AUC was significantly higher for RCWS $(0.83,95 \% \mathrm{Cl} 0.79-0.88)$ than for KTS $(0.71,95 \% \mathrm{Cl} 0.65-$ $0.76)$ and RTS $(0.70,95 \% \mathrm{Cl} 0.63-0.76)$ for all patients, but not for patients with complete data.

Conclusion: RCWS appears to predict surgical resource consumption better than KTS and RTS. RCWS may be a promising tool for planning and monitoring surgical care in resource-scarce conflict settings.

Keywords: Armed conflicts, Health resources, Penetrating wounds

\section{Background}

In armed conflicts, civilian causalities often must rely on frail and fragmented health care systems that can only offer limited or no surgical resources to treat injured with potentially life-threatening injuries [1]. For

\footnotetext{
* Correspondence: mans.muhrbeck@regionostergotland.se

'Department of Surgery in Norrköping, and Department of Biomedical and Clinical Sciences, Linköping University, Linköping, Sweden

Center for Disaster Medicine and Traumatology, University Hospital, Linköping, Sweden

Full list of author information is available at the end of the article
}

healthcare providers delivering surgical care in conflicts, it is therefore imperative to know how to use available surgical resources as efficiently as possible. The extent of surgical resource consumption or workload in resourcescarce conflict settings is often discussed in terms of the number of surgical procedures, amputations, use of blood products, and mortality rate [2-7]. However, to our knowledge, no method has been validated to predict these outcomes in conflict settings. Trauma scores developed and used in non-conflict trauma settings to

(c) The Author(s). 2021 Open Access This article is licensed under a Creative Commons Attribution 4.0 International License, which permits use, sharing, adaptation, distribution and reproduction in any medium or format, as long as you give appropriate credit to the original author(s) and the source, provide a link to the Creative Commons licence, and indicate if changes were made. The images or other third party material in this article are included in the article's Creative Commons licence, unless indicated otherwise in a credit line to the material. If material is not included in the article's Creative Commons licence and your intended use is not permitted by statutory regulation or exceeds the permitted use, you will need to obtain permission directly from the copyright holder. To view a copy of this licence, visit http://creativecommons.org/licenses/by/4.0/ The Creative Commons Public Domain Dedication waiver (http://creativecommons.org/publicdomain/zero/1.0/) applies to the data made available in this article, unless otherwise stated in a credit line to the data. 
predict mortality could potentially be used for this purpose. The vital sign-based Revised Trauma Score (RTS) has been shown to predict need for surgery, haemorrhage, and mortality [8-11]. In resource-scarce trauma settings the Kampala Score (KTS), a simplified combination of age, RTS and the anatomical-based Injury Severity Score (ISS), has been validated to predict the need for admission and mortality [12]. However, the predictive abilities for RTS and KTS could be diminished in conflicts due to disintegrated infrastructure, lack of transportation means, non-existing prehospital care and long distance to hospital that cause a survival bias where injured with life-threatening, but treatable, injuries die before reaching the hospital. Furthermore, injury patterns in armed conflicts are different from those seen in civilian traumas. Penetrating injuries are more prevalent, whereas blunt injuries are more frequent in civilian traumas $[13,14]$.

The International Committee of the Red Cross (ICRC) is a humanitarian organization providing medical assistance to victims of war and other situations of violence, including independently running or supporting hospitals. In the early 1990s Mr. Robin Coupland, at the time Chief Surgeon for ICRC, developed a system for wound classification (Red Cross Wound Score, RCWS) in order to help surgeons systematically describe penetrating wounds in conflicts [15]. To classify a wound according to RCWS, the extent of tissue damage (RCWS grade) and type of tissue involved (RCWS type) must be assessed (Table 1). The RCWS grade corresponds to amount of energy transferred to the tissue at time of injury [4, 15]. Studies have demonstrated that RCWS grade is associated with need of surgery, number of surgical procedures, in-hospital amputation, and mortality [4, 16-19]. However, RCWS predictive ability regarding the extent of surgical resource consumption and mortality has not previously been examined.

The aim of the present study was therefore to determine if RCWS, KTS and RTS have predictive abilities to assess the extent of surgical resource consumption as well as in-hospital mortality in resource-scarce conflict settings. Surgical resource consumption was characterized by the number of surgical procedures, blood transfusions and limb amputation. A secondary aim was to assess if the individual components of RCWS are independent predictors of surgical resource consumption and in-hospital mortality. If any of these scores could be found to be reliable, they would provide an urgently needed instrument for planning and monitoring surgical interventions in resource-scarce conflict settings.

\section{Patients and settings}

Routinely collected patient data from ICRC's hospitals in Peshawar, Pakistan, and Goma, the Democratic Republic
Table 1 Parameters included in the Red Cross Wound Score (RCWS) [4]

\begin{tabular}{|c|c|}
\hline $\begin{array}{l}\text { Wound } \\
\text { feature }\end{array}$ & Definition \\
\hline $\mathrm{E}$ (entry) & Entry wound in $\mathrm{cm}$ \\
\hline$X$ (exit) & Exit wound in $\mathrm{cm}$ ( $X=0$ if no exit) \\
\hline \multirow[t]{3}{*}{ C (cavity) } & $\begin{array}{l}\text { Can the cavity of the wound take two fingers before } \\
\text { surgical excision? }\end{array}$ \\
\hline & $\mathrm{CO}=\mathrm{No}$ \\
\hline & $\mathrm{C} 1=$ Yes \\
\hline \multirow[t]{4}{*}{ F (fracture) } & Fracture \\
\hline & $\mathrm{FO}=$ No fracture \\
\hline & $\mathrm{F} 1=$ Simple fracture, hole or insignificant comminution \\
\hline & F2 $=$ Clinically significant comminution \\
\hline \multirow{6}{*}{$\begin{array}{l}V \text { (vital } \\
\text { structure) }\end{array}$} & Injury threatening life or threatening life or limb \\
\hline & V0 $=$ No vital structure injured \\
\hline & $\begin{array}{l}\mathrm{VN}=\text { (neurological) penetration of the dura of the brain } \\
\text { or spinal cord }\end{array}$ \\
\hline & $\begin{array}{l}\mathrm{VT}=\text { (thorax or trachea) penetration of the pleura or of } \\
\text { the larynx/trachea in the neck }\end{array}$ \\
\hline & $V A=($ abdomen) penetration of the peritoneum \\
\hline & $\begin{array}{l}\mathrm{VH}=\text { (haemorrhage) injury of a major peripheral blood } \\
\text { vessel, down to the brachial artery in the arm or } \\
\text { the popliteal artery in the leg or carotid artery in the } \\
\text { neck }\end{array}$ \\
\hline
\end{tabular}

of the Congo (DRC), were retrospectively analysed for this study. Patients treated at ICRC's hospital in Peshawar were predominantly injured in the conflict on both sides of the Pakistani-Afghanistan border. The hospital was closed in 2014 and had 116 beds, a critical care unit, three operating theatres, X-ray services and a laboratory [20]. Patients treated at the hospital in Goma were mainly injured in the ongoing conflict between several rivalling factions in the Kivu province in the DRC. Compared to the conflict along the Afghanistan-Pakistani border, less injures from indiscriminate weapons such as grenades, bombs and anti-personnel mines have been reported [2, 20, 21]. The hospital is still operational and has 65 beds, one operating theatre, X-ray services and a laboratory. Both hospitals had access to physiotherapy for post-operative mobilization and rehabilitation with prosthesis fitting [20].

At both hospitals combatants as well as local citizens with weapon-related injuries were treated. Those seeking care were not asked whether they were civilians or combatants. Care at both hospitals was provided free of charge during the study period.

\section{Method}

The material consists of two matching databases of anonymized patient data from the ICRC's hospitals in Peshawar and Goma. All patients treated between 18 
February 2009-9 May 2012 (Peshawar) and 17 November 2012-17 September 2014 (Goma) were continuously included in the two databases (Excel ${ }^{\circ}$ spreadsheet) at the time of patient discharge. Entries in the Peshawar database were done by two physicians whose primary job was to maintain the database. Entries in the Goma database were done by health care staff after receiving basic training. In total 3028 patients were recorded in the Peshawar database and 689 in Goma database. The two databases were merged and transferred to SPSS Statistical software version 25 (IBM Corporation, Armonk, NY, USA) for this study. The final database was validated with respect to the original databases by comparing data from 50 patients from each database without any differences identified. Patients that fulfilled the following inclusion criteria were extracted from the merged database: adult patients with weapon-related penetrating injuries, assessed RCWS and known discharge status. Adults were defined as age 15 or older in accordance with previous studies from similar settings $[20,22]$. RCWS was determined by the surgeon at the time of the first surgical procedure according to ICRC guidelines [4]. Surgeons had received training in the use of RCWS prior to deployment. The wound with the highest RCWS grade and type was recorded as the first injury. To categorize a penetrating injury according to RCWS, the wound's grade 1-3 (wound's entry- and exit-diameter and if a two-fingers- wide cavity exists) and type (soft tissue, bones, threatening life or threatening life or limb) needs to be determined (Table 1).

Depending on the grade and type, a wound is assigned to one of twelve different categories (Additional Table 1) $[4,15,23]$. The presence of a second severe injury was dichotomously registered as existing or not. Severe injury was defined as a cavitating soft tissue injury with entry or exit $10 \mathrm{~cm}$ or more, or open fracture or injury to vital structure. This definition excludes RCWS soft tissue injury grade 1 and 2 and translates to an Abbreviated Injury Score of 2 or above for any given anatomical site, corresponding to the definition used in KTS [24]. In the case of multiple admissions only the first one was included. Patients with unspecified sex, time of injury and vital signs were considered to be incomplete cases and excluded in the primary analysis (Fig. 1).

ICRC characterizes surgical workload in conflict settings by severity of injuries, number of operations per patient, number of blood transfusions required and length of hospitalization [4]. To better reflect the actual surgical resource consumption, in the present study, this definition was modified to: number of surgical procedures under anaesthesia, blood transfusions and limb amputation. Length of hospitalization was excluded as this can be influenced by issues that are not related to the treatment of the patients' injuries. This modification was done after advice from senior ICRC surgeons, and is consistent with how surgical resource consumption is characterized in previous studies $[2-5,7,25]$.

High surgical resource consumption was dichotomously defined as:

1 Three or more surgical procedures under anaesthesia OR

2 Three or more blood transfusions OR

3 In-hospital amputation proximal to the metacarpophalangeal joints of the hand or the midtarsal joints of the foot.

Three or more surgical procedures were chosen because a study with 16,172 patients treated at ICRC's hospitals demonstrated that $66 \%$ of the patients were treated with two surgical procedures or fewer [4]. Three or more blood transfusions were chosen as a previous ICRC-study with 4470 weapon-injured patients demonstrated that $15.5 \%$ were transfused and an average of 2.9 units was given [25]. Furthermore, the ICRC recommends an availability of 100 units $/ 100$ patients if antipersonnel mines are used in the conflict [4]. In-hospital limb amputation was included as these patients require extensive resources postoperatively in terms of physiotherapy and prosthesis fitting. In-hospital mortality was defined as deceased during hospital stay.

\section{Statistical methods}

We estimated that 592 patients would be needed to detect a difference of 0.10 in the trauma scores' ability to detect high surgical resource consumption. A reference area under the receiver operating characteristic curve (AUC) of 0.75 , confidence interval (CI) $95 \%$ and power $90 \%$ was used for this sample size calculation. Nonetheless, all eligible patients were included in the analysis.

Descriptive comparisons between the hospitals in Peshawar and Goma were analysed using Fisher's exact test for categorical variables and Mann-Whitney $U$-test for continuous variables. Values are given as mean with standard deviation (SD) where appropriate. To compare the predictive effect of the individual components of RCWS, KTS and RTS on surgical resource consumption and in-hospital mortality, binary logistic regression was performed. Sex, age (15-49 and $>49$ yrs.), time since injury $(0-6,7-24$ and $>24 \mathrm{~h})$ systolic blood pressure $(0-$ $75,76-89$, and $>89 \mathrm{mmHg})$, respiratory rate $(\leq 9,10-29$, $\geq 30 / \mathrm{min})$, Glasgow Coma Scale $(\leq 5,6-8,9-12$ and $13-$ $15)$, RCWS grade, RCWS type and the existence of more than one severe injury were predictors included in the regression analysis as these are the components of RCWS, KTS and RTS or have in previous studies been identified as influencing the need for surgical intervention, blood transfusion or amputation [2, 26-29]. Vital 


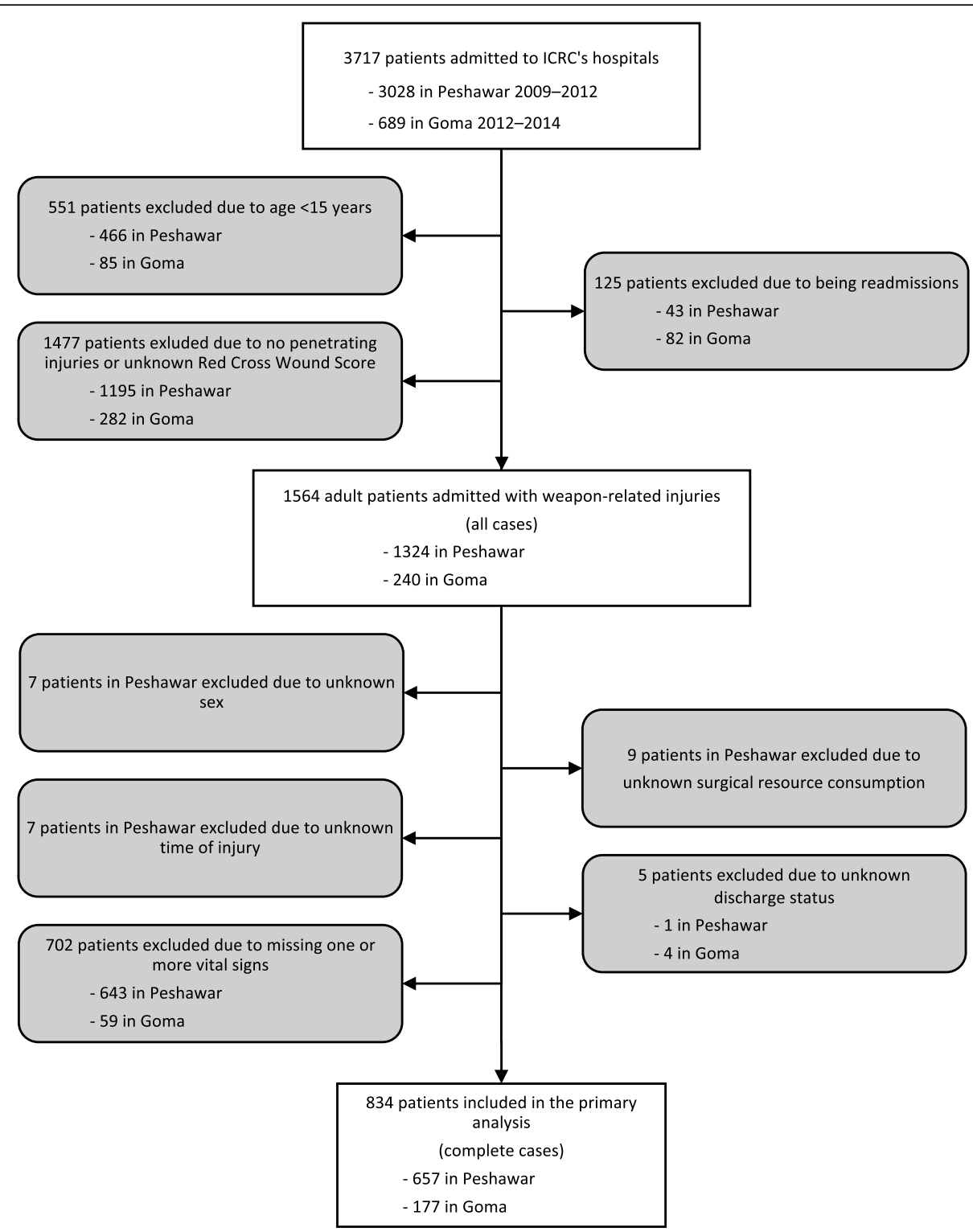

Fig. 1 Flow chart of inclusion. All patients $\geq 15$ years with weapon-related injuries classified with Red Cross Wound Score (RCWS), known surgical resource consumption and discharge status were included

signs were taken upon admission, and the intervals used match the intervals used in RTS [8]. The procedure to calculate RTS and KTS has been described elsewhere $[8$, 12]. Forward Wald was used to calculate a final regression model. When comparing differences in resource consumption for the Peshawar and Goma hospital, hospital site was added to the final regression model. The impact of predictors is presented as odds ratio (OR) with 95\% confidence intervals. $P$-values (two-tailed) less than 0.05 were considered significant for both the univariate and logistic regression analysis.

The sensitivity and specificity associated with the ability of RCWS, KTS and RTS to predict high surgical resource consumption and in-hospital mortality was assessed by analysing of the AUCs. To enable analysis of patients with more than one severe injury, RCWS was adjusted for the existence of additional severe injuries. In making comparisons of the prognostic abilities of RCWS, KTS and RTS regarding high surgical resource consumption and in-hospital mortality the AUCs along with 95\% CI were used. Overlapping confidence intervals were interpreted as indicating non-significant differences in the prognostic abilities of RCWS, KTS and RTS.

Comparison of goodness of model fit for RCWS, KTS and RTS in predicting high surgical resource consumption and in-hospital mortality was analysed by Akaike Information Criterion (AIC). A lower AIC score for a trauma score indicates a better fitting model in 
comparison with the other evaluated trauma scores. Little's MCAR test and imputation with fully conditional specification was done to enable the analysis of incomplete cases and thereby assessing the impact of exclusion of patients with unknown sex, time of injury and vital signs. Mann-Whitney $U$-test with Fisher's exact test was used to evaluate why a patient ended up in the high resource group.

\section{Results}

\section{Descriptive}

A total of 657 of 1324 patients treated in Peshawar and 177 of 240 patients treated in Goma had complete data (Complete cases, Fig. 1). There were more men and older patients injured in Peshawar compared to Goma, and more patients had injuries from indiscriminate weapons such as bombs, shells and fragments or antipersonnel mines, and fewer from gunshots $(p \leq 0.001$ for all) (Table 2).

There was no difference in the RCWS type for the first injury recorded between the hospitals. However, patients in Goma were more likely to be admitted within 6 hours of their injury or have injuries to the upper limbs, while patients in Peshawar more frequently had injuries to the head, face or more than one severe injury $(p<0.05$ for all) (Table 3).

Chest-tube insertion and fracture surgery were more frequent in Peshawar than in Goma $(p=0.039$ and $p<$ 0.001 , respectively). There was no difference in frequencies of amputations, surgical procedures, blood transfusions and in-hospital mortality between the hospitals (Table 4).

\section{Surgical resource consumption}

The relationship between surgical resource consumption, sex, age, vital signs and RCWS are shown in Table 5. A larger portion of the patients with high surgical resource consumption had lower systolic blood pressure, higher RCWS grade, higher RCWS type and more frequently had more than one severe injury compared to patients with low surgical resource consumption $(p<$

Table 2 Mechanism of injury for patients treated at ICRC'S hospitals in Peshawar and Goma

\begin{tabular}{llll}
\hline Mechanism & $\begin{array}{l}\text { Peshawar } \\
\text { Total }=657 \\
\mathbf{n}(\% \text { of total) }\end{array}$ & $\begin{array}{l}\text { Goma } \\
\text { Total }=177 \\
\mathbf{n}(\% \text { of total) }\end{array}$ & P value \\
\hline Gunshot & $357(54.3)$ & $156(88.1)$ & $<0.001$ \\
Bomb, shell, fragment & $266(40.5)$ & $17(9.6)$ & $<0.001$ \\
Anti-personnel mine & $31(4.7)$ & 0 & 0.001 \\
Arme blanche & $1(0.2)$ & $3(1.7)$ & 0.031 \\
Other & $2(0.3)$ & 0 & \\
Unknown & 0 & $1(0.6)$ & \\
\hline
\end{tabular}

0.01 for all). When adjusting for all predictors in the final logistic regression model RCWS grade, RCWS type and existence of more than one severe injury remained significant. Sex, age, time since injury, systolic blood pressure, respiratory rate and Glasgow Coma Scale did not affect a patient's surgical resource consumption.

For complete cases RCWS achieved significantly higher AUC and lower AIC, i.e., better predictive ability and model fit, than KTS and RTS for high surgical resource consumption (Table 6, Fig. 2). In the logistic regression model for all cases, using imputed data for incomplete cases, the same predictors plus age more than 49 years (OR 1.84, 95\% CI 1.26-2.70, $p<0.001$ ) were found to be significant (Additional Table 2). There was no statistically significant difference in the AUC for all cases compared to complete cases (Table 6 and Fig. 2).

\section{Subgroup analysis of high resource consumption and hospital site}

When hospital site was added to the final logistic regression model of complete cases, patients treated in Goma were more likely to have a high surgical resource

Table 3 Injury patterns for patients treated at ICRC's hospitals in Peshawar and Goma

\begin{tabular}{|c|c|c|c|}
\hline Injury patterns & $\begin{array}{l}\text { Peshawar } \\
\text { Total = } 657 \\
n \text { (\% of total) }\end{array}$ & $\begin{array}{l}\text { Goma } \\
\text { Total = } 177 \\
n \text { (\% of total) }\end{array}$ & $P$ value \\
\hline \multicolumn{4}{|l|}{ Location of injury ${ }^{a}$} \\
\hline Head or face & $58(8.8)$ & $6(3.4)$ & 0.016 \\
\hline Neck & $15(2.3)$ & $1(0.6)$ & 0.216 \\
\hline Thorax & $69(10.5)$ & $13(7.3)$ & 0.255 \\
\hline Back & $39(5.9)$ & $5(2.8)$ & 0.128 \\
\hline Abdomen & $30(4.6)$ & $13(7.3)$ & 0.178 \\
\hline Pelvis ${ }^{\mathrm{b}}$ & $26(4.0)$ & $9(5.1)$ & 0.527 \\
\hline Upper limbs & $136(20.7)$ & $50(28.2)$ & 0.042 \\
\hline Lower limbs & $276(42.0)$ & $76(43.0)$ & 0.864 \\
\hline Unknown & $8(1.2)$ & $4(2.3)$ & 0.294 \\
\hline \multicolumn{4}{|l|}{ RCWS type $^{a}$} \\
\hline Soft tissue & $225(34.2)$ & $62(35.0)$ & 0.859 \\
\hline Fracture & $269(40.9)$ & $75(42.4)$ & 0.732 \\
\hline Penetration of peritoneum & $38(5.8)$ & $17(9.6)$ & 0.086 \\
\hline Penetration of pleura $^{c}$ & $47(7.2)$ & $9(5.1)$ & 0.399 \\
\hline Penetration of dura ${ }^{d}$ & $34(5.2)$ & $5(2.8)$ & 0.231 \\
\hline Major periph. blood vessele & $44(6.7)$ & $9(5.1)$ & 0.492 \\
\hline Additional severe injuries ${ }^{f}$ & & & 0.005 \\
\hline No & $562(85.6)$ & $165(93.2)$ & \\
\hline Yes & $95(14.4)$ & $12(6.8)$ & \\
\hline
\end{tabular}

${ }^{\mathrm{a}}$ First injury recorded; ${ }^{\mathrm{b}}$ Pelvis including buttocks, perineum, and genitals; Including the larynx/trachea of the neck; ${ }^{\mathrm{d}}$ The dura of the brain or spinal cord; ${ }^{\mathrm{e}}$ Down to the brachial or popliteal or carotid arteries; ${ }^{\mathrm{f} C}$ Corresponding to Abbreviated Injury Score $\geq 2$ 
Table 4 Surgical care and in-hospital mortality for patients treated at ICRC's hospitals in Peshawar and Goma

\begin{tabular}{|c|c|c|c|c|c|}
\hline \multirow[t]{2}{*}{$\begin{array}{l}\text { Surgical care and in- } \\
\text { hospital morality }\end{array}$} & \multicolumn{2}{|l|}{$\begin{array}{l}\text { Peshawar } \\
\text { Total }=657\end{array}$} & \multicolumn{2}{|l|}{$\begin{array}{l}\text { Goma } \\
\text { Total = } 177\end{array}$} & \multirow[b]{2}{*}{$P$ value } \\
\hline & $\mathrm{n}$ (\% of total) & Mean (SD) & $\mathrm{n}$ (\% of total) & Mean (SD) & \\
\hline \multicolumn{6}{|c|}{ Surgical procedure under anesthesia ${ }^{a}$} \\
\hline Craniotomy & $21(3.2)$ & & $2(1.1)$ & & 0.195 \\
\hline Thoracotomy & $8(1.2)$ & & 0 & & 0.214 \\
\hline Chest-tube & $67(10.2)$ & & $9(5.1)$ & & 0.039 \\
\hline Laparotomy & $82(12.5)$ & & $14(7.9)$ & & 0.111 \\
\hline Peri. vasc. Repair & $31(4.7)$ & & $4(2.3)$ & & 0.148 \\
\hline Arm-amputation & $11(1.7)$ & & $3(1.7)$ & & 1 \\
\hline Leg-amputation & $34(5.2)$ & & $5(2.8)$ & & 0.122 \\
\hline Any amputation & $38(5.8)$ & $0.06(0.23)$ & $8(4.5)$ & $0.05(0.21)$ & $0.513^{d}$ \\
\hline Any frac. surgery ${ }^{b}$ & $157(23.9)$ & $0.24(0.43)$ & $18(10.2)$ & $0.10(0.30)$ & $<0.001^{\circ}$ \\
\hline Any soft tissue surgery ${ }^{c}$ & $608(92.5)$ & $0.93(0.26)$ & $170(96.0)$ & $0.96(0.20)$ & $0.098^{d}$ \\
\hline Any type of procedure & $637(97.0)$ & $0.97(0.17)$ & $168(94.9)$ & $0.95(0.22)$ & $0.188^{d}$ \\
\hline Blood transfusion & & $0.19(0.56)$ & & $0.34(1.19)$ & $0.521^{d}$ \\
\hline 0 units & $543(82.6)$ & & $153(86.4)$ & & 0.356 \\
\hline $1-2$ & $75(11.4)$ & & $15(8.5)$ & & 0.278 \\
\hline$\geq 3$ & $34(5.2)$ & & $9(5.1)$ & & 1 \\
\hline Unknown & $5(0.8)$ & & 0 & & 0.590 \\
\hline In-hospital mortality & & $0.03(0.16)$ & & $0.02(0.13)$ & $0.431^{d}$ \\
\hline No & 639 (97.3) & & 174 (98.3) & & \\
\hline Yes & $18(2.7)$ & & $3(1.7)$ & & \\
\hline
\end{tabular}

${ }^{\mathrm{a}}$ Some patients have been subjected to several procedures which results in more procedures than patients and sum of percentages more than $100 ;{ }^{b}$ External fixation, Kirchner wire, traction, or manipulation; ' ${ }^{C}$ Debridement, split skin graft, delayed primary closure, burn care, or change of dressing; ${ }^{\mathrm{d}} P$-value for comparison of mean

consumption than patients treated in Peshawar (OR $2.01,95 \%$ CI $1.36-2.98, p<0.001$ ). After adjusting surgical procedures shown in Table 3 for the total number of injured sites, patients in Goma were more frequently exposed to soft tissue surgery (Goma: mean 3.58 times/patient, SD 3.39, and Peshawar: 2.18, SD 1.75, $p<0.001$ ) and also to any type of surgical procedures under anaesthesia than in Peshawar (Goma: mean 3.71 times/patient, SD 3.71, and Peshawar: 1.96, SD 1.55, $p<0.001)$. When comparing Goma and Peshawar regarding patients with high surgical resource consumption the distribution between hospitals was similar regarding the number of surgical procedures, blood transfusions and amputation rates. Three or more surgical procedures most strongly explained why most patients ended up in the high resource consumption group for both hospital sites (Goma: 86 of 102 patients, 84.3\%, and Peshawar: 197 of 260 patients, $75.8 \%, p=0.09$ ).

\section{In-hospital mortality}

For in-hospital mortality, there was no difference between the hospitals (Peshawar: 18 patients, 2.7\% and
Goma: 3 patients, $1.7 \%, p=0.781$ ). At both hospitals, a larger portion of the patients who died in hospital arrived sooner after injury, had systolic blood pressure < $90 \mathrm{mmHg}, \mathrm{GCS}<13$ and higher RCWS type than those discharged alive ( $p<0.05$ for all) (Additional Table 3). In the logistical regression model for complete cases, no predictors were significant for in-hospital mortality. RCWS AUC and AIC for in-hospital mortality was not significantly better than KTS and RTS (Table 7, Fig. 3).

In the logistic regression model for all cases, using imputed data for incomplete cases, systolic blood pressure $76-89 \mathrm{mmHg}$ and RCWS types threatening life and threatening life or limb were found to be significant predictors for in-hospital mortality (systolic blood pressure 76-89 mmHg: OR 4.63, 95\% CI 1.59-13.44, threatening life: OR 10.72, 95\% 4.42-26.01 and threatening life or limb: $8.43,95 \%$ CI $3.36-21.18, p<0.01$ for all) (Additional Table 3). In the analysis of AUC for all cases RCWS demonstrated a significantly higher AUC and lower AIC, i.e. better predictive ability and model fit, than KTS and RTS for in-hospital mortality (Table 7 and Fig. 3). 
Table 5 Relationship between surgical resource consumption, sex, age, vital signs and Red Cross Wound Score (RCWS)

\begin{tabular}{|c|c|c|c|c|c|c|c|}
\hline \multirow[t]{2}{*}{$\begin{array}{l}\text { Surgical resource } \\
\text { consumption }\end{array}$} & \multicolumn{3}{|c|}{$\begin{array}{l}\text { Univariate analysis } \\
\text { Complete cases } \\
\text { Total }=834\end{array}$} & \multicolumn{4}{|c|}{$\begin{array}{l}\text { Logistic regression analysis } \\
\text { Complete cases } \\
\text { Total }=834\end{array}$} \\
\hline & $\begin{array}{l}\text { Low } \\
\text { Total }=472 \\
n(\%)\end{array}$ & $\begin{array}{l}\text { High }^{\mathrm{a}} \\
\text { Total = } 362 \\
\text { n (\%) }\end{array}$ & $P$ value & $\begin{array}{l}\text { All confounders } \\
1=\text { High }^{\mathrm{a}} \\
\text { Odds ratio }(95 \% \mathrm{Cl})\end{array}$ & $P$ value & $\begin{array}{l}\text { Final model (Wald) } \\
1=\text { High }^{\mathrm{a}} \\
\text { Odds ratio }(95 \% \mathrm{Cl})\end{array}$ & $P$ value \\
\hline Sex & & & 1.000 & & & & \\
\hline Male & $418(88.6)$ & $320(88.4)$ & & 1 & & & \\
\hline Female & $54(11.4)$ & $42(11.6)$ & & $1.14(0.68-1.90)$ & 0.626 & & \\
\hline Age & & & 0.710 & & & & \\
\hline $15-49$ years & $433(91.7)$ & $329(90.9)$ & & 1 & & & \\
\hline$>49$ & $39(8.3)$ & $33(9.1)$ & & $1.23(0.70-2.17)$ & 0.466 & & \\
\hline Time since injury & & & 0.152 & & & & \\
\hline $0-6 h$ & $15(3.2)$ & $21(5.8)$ & & 1 & & & \\
\hline $7-24 h$ & $203(43.0)$ & $159(43.9)$ & & $0.68(0.30-1.54)$ & 0.352 & & \\
\hline$>24 h$ & $254(53.8)$ & $182(50.3)$ & & $0.66(0.29-1.52)$ & 0.327 & & \\
\hline Systolic blood pressure & & & 0.004 & & & & \\
\hline$>89 \mathrm{mmHg}$ & $464(98.3)$ & $341(94.2)$ & & 1 & & & \\
\hline $76-89$ & $5(1.1)$ & $10(2.8)$ & & $1.16(0.33-4.11)$ & 0.931 & & \\
\hline $0-75$ & $3(0.6)$ & $11(3.0)$ & & $1.65(0.44-6.20)$ & 0.821 & & \\
\hline Respiratory rate & & & 0.446 & & & & \\
\hline 10-29/min & $458(97.0)$ & $347(95.9)$ & & 1 & & & \\
\hline$\leq 9$ & - & - & & - & - & & \\
\hline$\geq 30$ & $14(3.0)$ & $15(4.1)$ & & $0.88(0.37-2.09)$ & 0.772 & & \\
\hline Glasgow Coma Scale & & & 0.077 & & & & \\
\hline $13-15$ & $465(98.5)$ & $347(95.8)$ & & 1 & & & \\
\hline $9-12$ & $4(0.9)$ & $10(2.8)$ & & $1.09(0.31-3.87)$ & 0.896 & & \\
\hline $6-8$ & $2(0.4)$ & $4(1.1)$ & & $1.60(0.22-11.65)$ & 0.644 & & \\
\hline$\leq 5$ & $1(0.2)$ & $1(0.3)$ & & $0.84(0.05-15.76)$ & 0.906 & & \\
\hline RCWS grade & & & $<0.001$ & & & & \\
\hline 1 (simple) & $266(56.4)$ & $83(22.9)$ & & 1 & & 1 & \\
\hline 2 (medium) & $185(39.2)$ & $178(49.2)$ & & $2.60(1.81-3.74)$ & $<0.001$ & $2.63(1.84-3.76)$ & $<0.001$ \\
\hline 3 (large) & $21(4.4)$ & $101(27.9)$ & & $11.60(6.61-20.36)$ & $<0.001$ & $11.94(6.85-20.80)$ & $<0.001$ \\
\hline RCWS type & & & $<0.001$ & & & & \\
\hline Soft tissue & $220(46.6)$ & $67(18.5)$ & & 1 & & 1 & \\
\hline Fracture & $164(34.8)$ & $180(49.7)$ & & $2.39(1.62-3.54)$ & $<0.001$ & $2.32(1.58-3.41)$ & $<0.001$ \\
\hline Threatening life & $59(12.5)$ & $45(12.4)$ & & $2.16(1.27-3.67)$ & 0.005 & $2.20(1.31-3.72)$ & 0.003 \\
\hline Threatening life/limb & $29(6.1)$ & $70(19.4)$ & & $4.67(2.61-834)$ & $<0.001$ & $4.80(2.77-8.33)$ & $<0.001$ \\
\hline Additional severe injuries $^{\mathrm{b}}$ & & & $<0.001$ & & & & \\
\hline No & $439(93.0)$ & $288(79.6)$ & & 1 & & 1 & \\
\hline Yes & $33(7.0)$ & $74(20.4)$ & & $2.90(1.83-4.89)$ & $<0.001$ & $3.00(1.85-4.88)$ & $<0.001$ \\
\hline
\end{tabular}

\section{Discussion}

To our knowledge, this is the first study to reveal that RCWS could have predictive abilities for high surgical resource consumption in adult patients with weaponrelated injuries. This finding is consistent with previous studies that have demonstrated a relationship between RCWS and the need for surgery, number of procedures, in-hospital amputation and mortality [16-19]. Furthermore, in a recent study from our group findings suggest that RCWS grade is correlated with number of surgeries, 
Table 6 Analysis of AUC and AIC for individual scores for high surgical resource consumption

\begin{tabular}{|c|c|c|c|c|}
\hline \multirow{2}{*}{$\begin{array}{l}\text { High } \\
\text { surgical } \\
\text { resource } \\
\text { consumption }\end{array}$} & \multicolumn{2}{|l|}{$\begin{array}{l}\text { Complete cases } \\
\text { Total }=834\end{array}$} & \multicolumn{2}{|l|}{$\begin{array}{l}\text { All cases }{ }^{\mathrm{a}} \\
\text { Total }=1555^{\mathrm{b}}\end{array}$} \\
\hline & AUC (95\% Cl) & AIC & AUC (95\% Cl) & AIC \\
\hline$\overline{R C W S^{C}}$ & $0.77(0.74-0.81)$ & 904 & $0.76(0.74-0.78)$ & 1777 \\
\hline - Grade & $0.74(0.70-0.77)$ & 948 & $0.73(0.71-0.76)$ & 1833 \\
\hline - Type ${ }^{c}$ & $0.70(0.67-0.74)$ & 1010 & $0.67(0.65-0.70)$ & 1979 \\
\hline TS & $0.59(0.55-0.63)$ & 1114 & $0.53(0.50-0.56)$ & 2072 \\
\hline TS & $0.54(0.50-0.58)$ & 1145 & $0.51(0.48-0.54)$ & 2096 \\
\hline
\end{tabular}

a Using imputed data for incomplete cases; ${ }^{b} 9$ patients excluded due to unknown surgical resource consumption; 'Adjusted for existence of additional severe injuries, corresponding to Abbreviated Injury Score $\geq 2$

blood transfusions and hospital stay in paediatric patients with weapon-related extremity wounds [30].

When comparing RCWS with KTS and RTS, commonly used trauma scores in non-conflict settings, RCWS had a better ability to predict high surgical resource consumption in conflict settings [11, 24, 31]. KTS and RTS were chosen for comparison as they have been demonstrated to be able to predict resource-related outcomes in trauma settings [10-12, 32, 33]. Furthermore, RCWS, KTS and RTS are similar in the aspect that they can be assessed without the need of advanced diagnostic equipment or calculations. A source of error is that we had a large number of missing vital signs in our dataset
Table 7 Analysis of AUC and AIC for individual scores for inhospital mortality

\begin{tabular}{|c|c|c|c|c|}
\hline \multirow{2}{*}{$\begin{array}{l}\text { In- } \\
\text { hospital } \\
\text { mortality }\end{array}$} & \multicolumn{2}{|l|}{$\begin{array}{l}\text { Complete cases } \\
\text { Total }=834\end{array}$} & \multicolumn{2}{|l|}{$\begin{array}{l}\text { All cases }{ }^{\mathrm{a}} \\
\text { Total }=1559^{\mathrm{b}}\end{array}$} \\
\hline & AUC (95\% Cl) & $\mathrm{AIC}$ & AUC (95\% Cl) & AIC \\
\hline$\overline{\text { RCWS }^{\mathrm{C}}}$ & $0.77(0.67-0.86)$ & 180 & $0.83(0.79-0.88)$ & 481 \\
\hline - Grade & $0.56(0.42-0.70)$ & 176 & $0.59(0.52-0.66)$ & 582 \\
\hline - Type ${ }^{c}$ & $0.73(0.62-0.84)$ & 193 & $0.78(0.73-0.84)$ & 506 \\
\hline KTS & $0.74(0.62-0.87)$ & 183 & $0.71(0.65-0.76)$ & 537 \\
\hline RTS & $0.67(0.54-0.81)$ & 182 & $0.70(0.63-0.76)$ & 534 \\
\hline
\end{tabular}

${ }^{\mathrm{a}}$ Using imputed data for incomplete cases; ${ }^{\mathrm{b}} 5$ patients excluded due to unknown discharge status; ${ }^{\mathrm{C}} \mathrm{Adjusted}$ for existence of additional severe injuries, corresponding to Abbreviated Injury Score $\geq 2$

potentially affecting the predictive abilities for KTS and RTS. To address this issue, we performed the logistic regression model with imputed data for missing vital signs without any substantial changes in vital signs impact on surgical resource consumption.

Patients treated in Peshawar were more frequently injured by indiscriminate weapons, arrived later to the hospital and more often had more than one severe injury than in Goma. Therefore, it was unexpected to find that the patients in Goma more often required high surgical resources than in Peshawar. The reason for the observed difference in surgical resource consumption is unclear as both hospitals followed the same treatment protocol and were similarly equipped [20]. A possible explanation
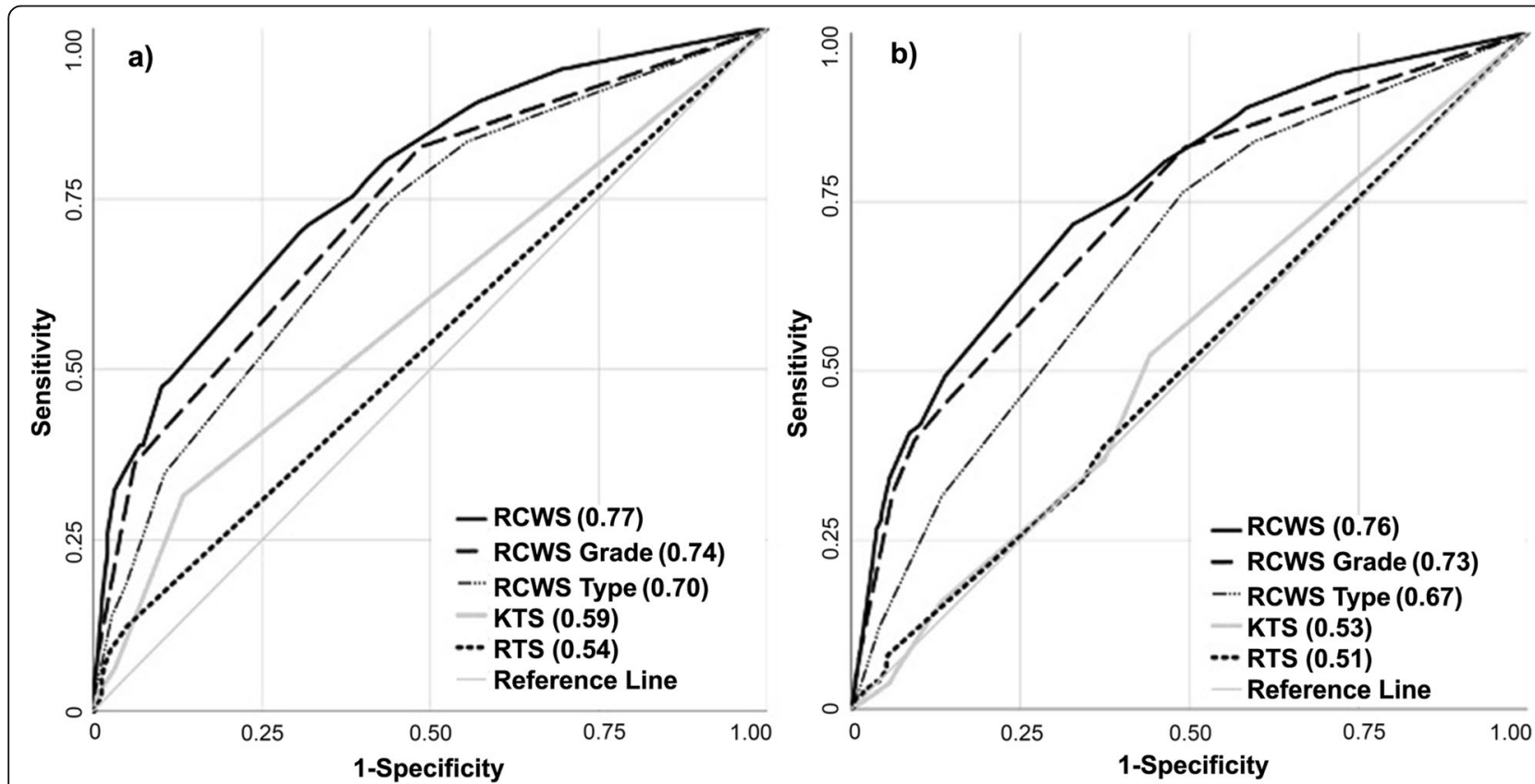

Fig. 2 High surgical resource consumption by RCWS, KTS and RTS. AUC in parenthesis. Note that RCWS, RCWS grade and RCWS type were adjusted for existence of additional severe injuries, corresponding to Abbreviated Injury Score $\geq 2$. a Complete cases $(n=834)$. b All cases using imputed data for incomplete cases ( $n=1555.9$ patients excluded due to unknown surgical resource consumption) 

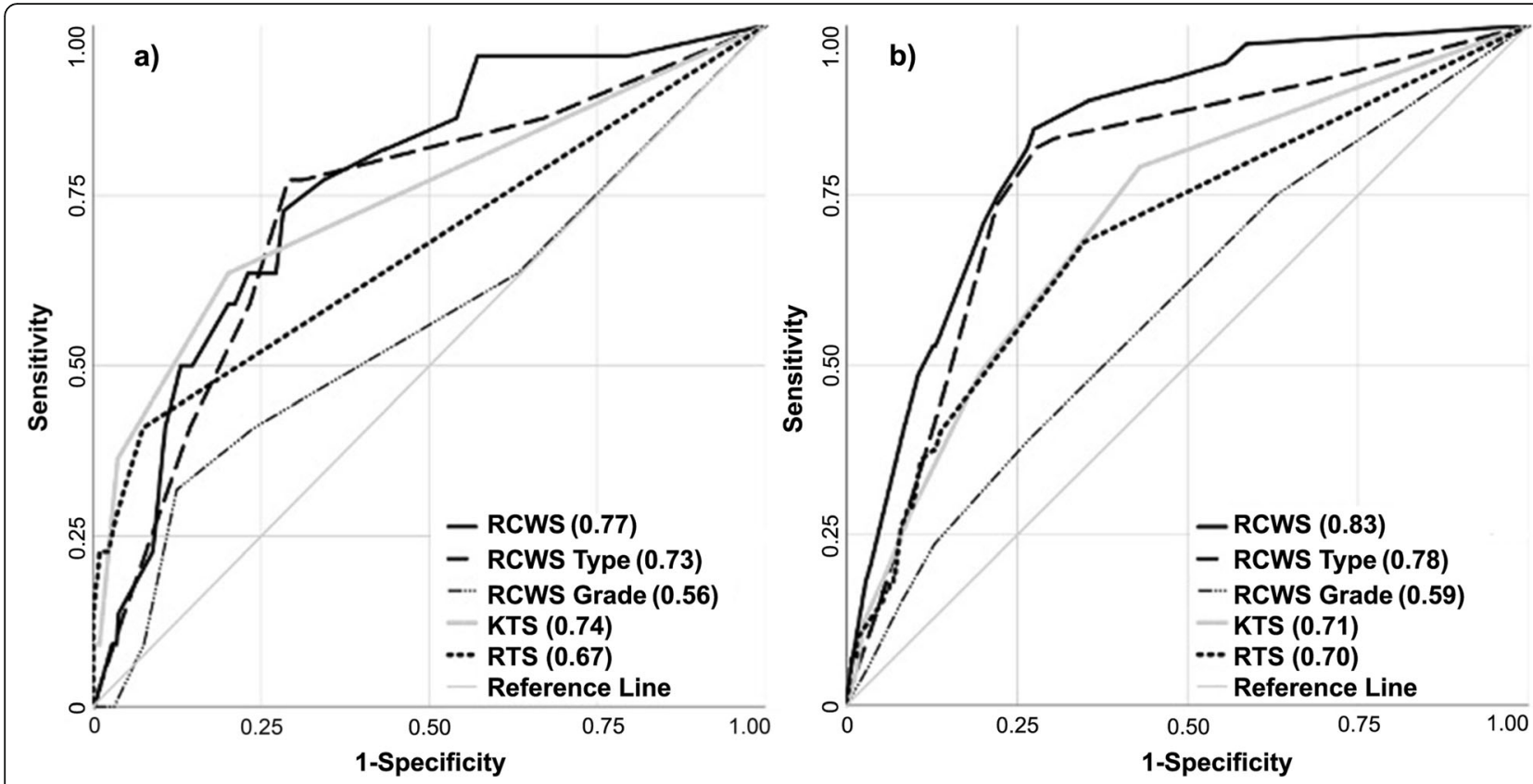

Fig. 3 In-hospital mortality by RCWS, KTS and RTS. AUC in parenthesis. Note that RCWS, RCWS grade and RCWS type were adjusted for existence of additional severe injuries, corresponding to Abbreviated Injury Score $\geq 2$. a Complete cases $(n=834)$. b All cases using imputed data for incomplete cases ( $n=1559.5$ patients excluded due to unknown discharge status)

could be that patients treated in Goma were in a poorer general condition with impaired healing ability due to being more frequently affected by malnutrition or endemic diseases such as tuberculosis and malaria compared to Peshawar [34]. This difference in consumption of surgical resources between Goma and Peshawar illustrates how RCWS potentially could be used to systematically evaluate treatment facilities use of surgical resources in relation to injuries treated.

Consistent with other studies from armed conflicts, a low in-hospital mortality was observed at both hospitals $[4,20,35]$. In the analysis of all cases systolic blood pressure $76-89 \mathrm{mmHg}$, RCWS types threatening life and threatening life or limb were found to be significant predictors for in-hospital mortality rendering significantly better predictive ability for RCWS than KTS and RTS. The grade component of RCWS has previously been found to be associated with mortality in patients with conflict-related abdominal wounds with penetration of the peritoneum [19]. Otherwise, little has previously been known regarding RCWS predictive ability for mortality. In non-conflict settings better predictive abilities for KTS and RTS regarding mortality following weaponrelated injuries have been reported [36, 37]. The worse predictive ability observed in our study could be explained by the survival bias where patients with the most altered vital signs die before reaching the hospital. The low in-hospital mortality and that over $90 \%$ of the patients in our material arrived more than 6 hours after the injury occurred supports this assumption. The conclusion that RCWS has better predictive ability for inhospital mortality than KTS and RTS in conflicts must therefore be made with caution.

The difficulty to foresee what resources will be needed in conflicts coupled with fragile and unreliable supply chains can potentially lead to disastrous effects in terms of morbidity and mortality [4,38]. Our findings support the use of RCWS as an instrument for evaluation of surgical resource needs and in-hospital mortality in relation to injuries treated. RCWS could consequently be used to ensure that the surgical resources provided meet the actual treatment needs. The systematic use of RCWS could also enable quality audits and research in conflict settings. The inclusion of RCWS in the minimum data set recommended by the Consensus Framework for the $\mathrm{Hu}$ manitarian Surgical Response to 21st Century Warfare should therefore be considered [39]. However, prospective studies from different armed conflicts are needed to assess the external validity of our findings and determine the predictive ability for each RCWS category. Furthermore, the interobserver reliability for RCWS needs to be evaluated.

\section{Limitations}

The use of routinely collected patient data limits the possibility of controlling for potentially confounding factors, such as variations in workload, adherence to treatment protocols, access to drugs, blood products, 
disposable material, and missing data. To mitigate the issue with missing data, we also analysed the predictive abilities for RCWS, KTS and RTS using an imputed dataset, with only minor alterations in the results. Nevertheless, alternative explanations for our findings could exist. A prospective cohort study design would have allowed for better control of confounding factors. However, prospective data collection in conflict settings is often difficult due to restraints in infrastructure and frequent rotation of health care staff. Additionally, participation in a study can have negative implications for participating health care staff and patients.

\section{Conclusion}

Our findings indicate that RCWS was able to predict high surgical resource consumption better than and inhospital mortality at least equal to KTS and RTS. In addition to facilitating systematic evaluation of penetrating injuries RCWS could consequently be a useful instrument in planning and monitoring of surgical care facilities in resource-scarce conflict settings. However, future studies are needed to determine RCWS predictive ability and interobserver variability in different conflicts and for different care providers.

\section{Abbreviations}

AIC: Akaike Information Criterion; AUC: Area under the receiver operating characteristic curve; Cl: Confidence interval; ICRC: International Committee of the Red Cross; ISS: Injury Severity Score; KTS: Kampala Trauma Score; OR: Odds ratio; RCWS: Red Cross Wound Score; RTS: Revised Trauma Score; SD: Standard deviation

\section{Supplementary Information}

The online version contains supplementary material available at https://doi. org/10.1186/s12873-021-00488-2.

Additional file 1: Table 1. Explanation on how to classify penetrating injuries according to Red Cross Wound Score (RCWS).

Additional file 2: Table 2. Relationship between surgical resource consumption, sex, age, vital signs and Red Cross Wound Score (RCWS). Table of univariate and logistic regression analysis examining the relationship between surgical resource consumption, sex, age, vital signs, RCWS grade and type forpatients treated at ICRC's hospitals in Peshawar and Goma.

Additional file 3: Table 3. Relationship between in-hospital mortality, sex, age, vital signs and Red Cross Wound Score (RCWS). Table of univariate and logistic regression analysis examining the relationship between in-hospital mortality, sex, age, vital signs RCWS grade and type for patients treated at ICRC's hospitals in Peshawar and Goma.

\section{Acknowledgements}

Preliminary results were presented orally at the Swedish Surgical Society annual meeting, August 22-26, 2016, Malmö, Sweden, and at the 6th World Society of Emergency Surgery annual meeting, June 26-28, 2019, Nijmegen, the Netherlands, and an abstract was orally presented at the 20th WADEM Congress on Disaster and Emergency Medicine, April 25-28, 2017, Toronto, Canada. Open access funding was provided by Linköping University. We thank former ICRC chief surgeons Robin M. Coupland and Harald Veen for providing indispensable input on how to define surgical resource consumption and Lars Valter, Forum Östergötland, Linköping University, Sweden, for statistical advice.

\section{Authors' contributions}

This study was conceived and designed by MM, JvS and PA. Data were collected by ZO in Peshawar and ICRC-staff in Goma and analysed by MM and PA. Interpretation of data was done by MM, ZO, JvS, AW and PA (all authors). First draft of the manuscript was made by MM and was critically revised by all authors. Final version of the manuscript was read and approved by all authors.

\section{Funding}

This study was supported by grants from Region Östergötland (ALF LIO79962 and RALF 06000908), Sweden. Region Östergötland did not have any influence in the design of the study or in the collection, analysis, and interpretation of data or in writing of the manuscript. Open Access funding provided by Linköping University.

\section{Availability of data and materials}

The datasets used and analysed during the current study are available from the corresponding author on reasonable request.

\section{Declarations}

\section{Ethics approval and consent to participate}

The data utilized in the present study emanates from areas with ongoing armed conflict where academic institutions are non- or malfunctioning, making local ethics approvals not possible to obtain. Furthermore, as this study is a secondary analysis of previously collected non-identifiable quality control data from ICRC-operated hospitals local ethics approvals and consents were not deemed necessary. However, to ensure that ethical standards were met, ethical approval for exploration and compilation of data for scientific presentation was obtained from the Regional Ethical Review Board in Linköping, Swedish Ethical Review Authority, approval numbers 2014/417-31, 2015/66-33 and 2016/298-32. The ICRC approved the study and gave all necessary administrative permissions. The study was performed in accordance with the ethical standards stipulated by Linköping University and the Declaration of Helsinki.

\section{Consent for publication}

Publication of this study was approved by the ICRC.

\section{Competing interests}

The authors have no conflicts of interest to declare. ZO has a long-term contract at the ICRC, AW was Chief Surgeon at the ICRC 2017-2019 and PA has had several intermittent contracts with the ICRC.

\section{Author details}

${ }^{1}$ Department of Surgery in Norrköping, and Department of Biomedical and Clinical Sciences, Linköping University, Linköping, Sweden. ${ }^{2}$ Center for Disaster Medicine and Traumatology, University Hospital, Linköping, Sweden. ${ }^{3}$ International Committee of the Red Cross, Geneva, Switzerland. ${ }^{4}$ Department of Global Public Health, Karolinska Institutet, Stockholm, Sweden. ${ }^{5}$ International Medical Programme, Center for Disaster Medicine and Traumatology, University Hospital, Linköping, Sweden.

Received: 13 December 2020 Accepted: 30 July 2021

Published online: 11 August 2021

References

1. Leaning J, Guha-Sapir D. Natural disasters, armed conflict, and public health. N Engl J Med. 2013;369(19):1836-42 https://doi.org/10.1056/NEJMra1 109877.

2. Andersson P, Muhrbeck M, Veen H, Osman Z, von Schreeb J. Hospital workload for weapon-wounded females treated by the International Committee of the red Cross: more work needed than for males. World J Surg. 2018;42(1):93-8 https://doi.org/10.1007/s00268-017-4160-y.

3. Gertsch P. Assessment of hospital workload in war surgery. Br I Surg. 1987; 74(9):831-3 https://doi.org/10.1002/bjs.1800740928.

4. Giannou C, Baldan M. War surgery: working with limited resources in armed conflict and other situations of violence, vol. 1. Geneva: International Committee of the Red Cross; 2019

5. Coupland RM, Korver A. Injuries from antipersonnel mines. The experience of the International Committee of the red Cross. BMJ. 1991;303(6816):150912 https://doi.org/10.1136/bmj.303.6816.1509. 
6. Ramalingam T. Extremity injuries remain a high surgical workload in a conflict zone: experiences of a British field hospital in Iraq, 2003. JRAMC. 2004;150(3):187-90 https://doi.org/10.1136/jramc-150-03-06.

7. Korver AJ. Injuries of the lower limbs caused by antipersonnel mines: the experience of the International Committee of the red Cross. Injury. 1996; 27(7):477-9 https://doi.org/10.1016/0020-1383(96)00066-6.

8. Champion HR, Sacco WJ, Copes WS, Gann DS, Gennarelli TA, Flanagan ME. A revision of the trauma score. J Trauma. 1989;29(5):623-9 https://doi.org/1 0.1097/00005373-198905000-00017.

9. Roy N, Gerdin M, Schneider E, Kizhakke Veetil DK, Khajanchi M, Kumar V, et al. Validation of international trauma scoring systems in urban trauma centres in India. Injury. 2016;47(11):2459-64 https://doi.org/10.1016/j.injury.2016.09.027.

10. Emerman CL, Shade B, Kubincanek J. A comparison of EMT judgment and prehospital trauma triage instruments. J Trauma. 1991;31(10):1369-75 https://doi.org/10.1097/00005373-199110000-00009.

11. Raux M, Sartorius D, Le Manach Y, David JS, Riou B, Vivien B. What do prehospital trauma scores predict besides mortality? J Trauma. 2011;71(3): 754-9 https://doi.org/10.1097/ta.0b013e3181fd0dae.

12. Kobusingye OC, Lett RR. Hospital-based trauma registries in Uganda. J Trauma. 2000;48(3):498-502 https://doi.org/10.1097/00005373-200003000-00022.

13. Wild H, Stewart BT, LeBoa C, Stave CD, Wren SM. Epidemiology of injuries sustained by civilians and local combatants in contemporary armed conflict: an appeal for a shared trauma registry among humanitarian actors. World J Surg. 2020;44(6):1863-73 https://doi.org/10.1007/s00268-020-05428-y.

14. Søreide K. Epidemiology of major trauma. Br J Surg. 2009;96(7):697-8 https://doi.org/10.1002/bjs.6643.

15. Coupland RM. The red cross classification of war wounds: the E.X.C.F.V. M. scoring system. World J Surg. 1992;16(5):910-7 https://doi.org/10.1 007/bf02066991.

16. Coupland RM. Hand grenade injuries among civilians. JAMA. 1993;270(5): 624-6 https://doi.org/10.1001/jama.1993.03510050090034.

17. Muhrbeck M, Holmgren K, Osman Z, von Schreeb J, Wladis A, Andersson P. Trends in demographics and surgical treatment of weapon-related limb injuries over two decades in a resource-scarce setting. World J Surg. 2019; 43(11):2681-8 https://doi.org/10.1007/s00268-019-05110-y.

18. Hinsley DE, Rosell PA, Rowlands TK, Clasper JC. Penetrating missile injuries during asymmetric warfare in the 2003 gulf conflict. Br J Surg. 2005;92(5): 637-42 https://doi.org/10.1002/bjs.4911.

19. Coupland RM. Abdominal wounds in war. Br J Surg. 1996;83(11):1505-11 https://doi.org/10.1002/bjs.1800831106.

20. Haverkamp FJC, van Gennip L, Muhrbeck M, Veen H, Wladis A, Tan E. Global surgery for paediatric casualties in armed conflict. World J Emerg Surg. 2019;14(1):55. https://doi.org/10.1186/s13017-019-0275-9.

21. Chu K, Havet P, Ford N, Trelles M. Surgical care for the direct and indirect victims of violence in the eastern Democratic Republic of Congo. Confl Health. 2010;4(1):6. https://doi.org/10.1186\%2F1752-1505-4-6.

22. Wagner Z, Heft-Neal S, Wise PH, Black RE, Burke M, Boerma T, et al. Women and children living in areas of armed conflict in Africa: a geospatial analysis of mortality and orphanhood. Lancet Glob Health. 2019;7(12):e1622-e31 https://doi.org/10.1016/s2214-109x(19)30407-3.

23. Coupland RM. The red cross wound classification. Geneva: International Committee of the Red Cross; 1993.

24. MacLeod JBA, Kobusingye O, Frost C, Lett R, Kirya F, Shulman CA Comparison of the Kampala trauma score (KTS) with the revised trauma score (RTS), injury severity score (ISS) and the TRISS method in a Ugandan trauma registry. Eur J Trauma. 2003;29(6):392-8 https://doi.org/10.1007/ s00068-003-1277-5.

25. Eshaya-Chauvin B, Coupland RM. Transfusion requirements for the management of war injured: the experience of the International Committee of the red Cross. Br J Anaesth. 1992;68(2):221-3 https://doi. org/10.1093/bja/68.2.221.

26. Forrester JD, Forrester JA, Basimouneye JP, Tahir MZ, Trelles M, Kushner $A L$, et al. Sex disparities among persons receiving operative care during armed conflicts. Surgery. 2017;162(2):366-76 https://doi.org/10.1016/j. surg.2017.03.001.

27. Azad AD, Kong W, Clarke DL, Laing GL, Bruce JL, Chao TE. Use of vital signs in predicting surgical intervention in a south African population: a crosssectional study. Int J Surg. 2020;7(79):300-4 https://doi.org/10.1016/j.ijsu.202 0.05.013.

28. Kotwal RS, Howard JT, Orman JA, Tarpey BW, Bailey JA, Champion HR, et al. The effect of a golden hour policy on the morbidity and mortality of combat casualties. JAMA Surg. 2016;151(1):15-24 https://doi.org/10.1001/ja masurg.2015.3104.

29. Davidovic LB, Cinara IS, IIle T, Kostic DM, Dragas MV, Markovic DM. Civil and war peripheral arterial trauma: review of risk factors associated with limb loss. Vascular. 2005;13(3):141-7 https://doi.org/10.1258/rsmvasc.13.3.141.

30. van Gennip L, Haverkamp FJC, Muhrbeck M, Wladis A, Tan E. Using the red cross wound classification to predict treatment needs in children with conflict-related limb injuries: a retrospective database study. World J Emerg Surg. 2020;15(1):52 https://doi.org/10.1186/s13017-020-00333-0.

31. Weeks SR, Juillard CJ, Monono ME, Etoundi GA, Ngamby MK, Hyder AA, et al. Is the Kampala trauma score an effective predictor of mortality in lowresource settings? A comparison of multiple trauma severity scores. World J Surg. 2014;38(8):1905-11 https://doi.org/10.1007/s00268-014-2496-0.

32. Haac B, Varela C, Geyer A, Cairns B, Charles A. The utility of the Kampala trauma score as a triage tool in a sub-Saharan African trauma cohort. World J Surg. 2015;39(2):356-62 https://doi.org/10.1007/s00268-014-2830-6.

33. Gardner A, Forson PK, Oduro G, Stewart B, Dike N, Glover P, et al. Diagnostic accuracy of the Kampala trauma score using estimated abbreviated injury scale scores and physician opinion. Injury. 2017;48(1):177-83 https://doi. org/10.1016/j.injury.2016.11.022

34. Institute for Health Metrics and Evaulation (IHME). GBD Compare Data Visualization. Seattle, WA:IHME, University of Washington. Available from http://vizhub.healthdata.org/gbd-compare (Accessed 15 Apr 2020).

35. Trelles M, Stewart BT, Hemat H, Naseem M, Zaheer S, Zakir M, et al. Averted health burden over 4 years at Medecins sans Frontieres (MSF) trauma Centre in Kunduz, Afghanistan, prior to its closure in 2015. Surgery. 2016; 160(5):1414-21 https://doi.org/10.1016/j.surg.2016.05.024.

36. Aspelund $A L$, Patel MQ, Kurland L, McCaul M, van Hoving DJ. Evaluating trauma scoring systems for patients presenting with gunshot injuries to a district-level urban public hospital in Cape Town, South Africa. Afr J Emerg Med. 2019;9(4):193-6 https://doi.org/10.1016/j.afjem.2019.07.004.

37. Arikan AA, Selcuk E, Bayraktar FA. Predicting outcomes of penetrating cardiovascular injuries at a rural center by different scoring systems. Braz J Cardiovasc Surg. 2020;35(2):198-205 https://doi.org/10.21470/1 678-9741-2019-0403.

38. Debarre A. Hard to reach: providing healthcare in armed conflict. New York: International Peace Institute; 2018. Available from https://www. ipinst.org/wp-content/uploads/2018/12/1812_Hard-to-Reach.pdf (Accessed 10 Dec 2020)

39. Wren SM, Wild HB, Gurney J, Amirtharajah M, Brown ZW, Bulger EM, et al. A consensus framework for the humanitarian surgical response to armed conflict in 21st century warfare. JAMA Surg. 2019;155(2):114-21 https://doi. org/10.1001/jamasurg.2019.4547.

\section{Publisher's Note}

Springer Nature remains neutral with regard to jurisdictional claims in published maps and institutional affiliations.

Ready to submit your research? Choose BMC and benefit from:

- fast, convenient online submission

- thorough peer review by experienced researchers in your field

- rapid publication on acceptance

- support for research data, including large and complex data types

- gold Open Access which fosters wider collaboration and increased citations

- maximum visibility for your research: over $100 \mathrm{M}$ website views per year

At $\mathrm{BMC}$, research is always in progress.

Learn more biomedcentral.com/submissions 